\title{
Combined Irradiation-Heat Processing of Canned Foods : Green Peas Inoculated with Anaerobic Bacterial Spores
}

\author{
Lloy d L. Kempe, John T. Gratkoski and Peter F. Bonventre, \\ Departments of Chemical Engineering and Bacteriology, University \\ of Michigan, Ann Arbor, Michigan
}

Summary. Combined irradiation-heat processing is shown to be synergistic for killing anaerobic bacterial spores inoculated into canned green peas. Following 1.2 megarad of gamma irradiation an $F_{0}$ of 0.5 sterilized green peas inoculated with either 5,000,000 Clostridium botulinum $213 \mathrm{~B}$ or 300 PA 3679 spores per can. This processing schedule must be cunsidered a minimum since it is based on a limited number of cans. Because sterilization by either irradiation or heat alone can damage the organoleptic properties of canned foods, the lowered schedules possible with combined processing may prove to be of value for preserving vegetables as well as meats.

\section{Introduction}

Combined irradiation-heat processing is shown to be synergistic for killing anaerobic bacterial spores inoculated into canned peas. This had previously been demonstrated with canned meat (Kempe et al., 1957; 1959). It had also been shown that sterilizing doses of either heat or ionizing radiations often lower the organoleptic qualities of foods, but that smaller dosages may be acceptable (Schultz et al., 1956). Since reduced quantities of gamma radiation and heat are required when their synergistic effect on bacterial spores is utilized, combined processing could become useful for food preservation. For this reason, it was considered desirable to learn whether combined irradiation-heat processing was also effective in canned vegetables. Green peas were selected for study because they are packed commercially and are a good growth medium for anaerobic bacterial spores (Reed et al., 1951). 


\section{Materials and Methods}

\section{A. Packing}

Commercially frozen green peas were obtained in $2.5 \mathrm{lb}$ boxes from the stock supply of the University of Michigan Food Service. Labels on the packages indicated that the peas contained a 'slight amount' of added salt.

In preparation for a run, $15 \mathrm{lb}$ of the frozen peas were placed in a stock pot and these were covered with a brine containing 1.8 per cent sodium chloride and $2 \cdot 2$ per cent sucrose. This brine was previously described for peas by Reed et al. (1951). The stock pot was then placed in a boiling water bath for about $1.5 \mathrm{~h}$ during which time the frozen peas melted and were brought to a temperature of $205^{\circ} \mathrm{F}$.

Number 1 picnic tin cans were filled with peas to within $\frac{1}{4}$ in. of the top; care was taken to cover the peas with brine. Covers were placed loosely on the cans that were then set in an autoclave which was filled with flowing steam. After the canned peas had been exhausted for a few minutes, individual cans were removed from the autoclave, inoculated at the gəometrical centre with $1 \mathrm{ml}$ of a spore suspension, sealed in a commercial-type closing machine, immersed in cold, running water for $20 \mathrm{~min}$, and then refrigerated until they were either irradiated, heat-processed, or incubated at $85^{\circ} \mathrm{F}$ as required.

\section{B. Irradiation}

The canned peas were irradiated in the centre-well of the large cobalt-60 gamma radiation source in the Fission Products Laboratory at the University of Michigan (Lewis et al., 1954). The quantity of irradiation delivered at the centre of the cans was measured by ferrous-ferric sulphate dosimetry as previously described (Kempe et al., 1954). At the time of this investigation, a dosage of 1 megarad* of gamma radiation required approximately $8 \mathrm{~h}$ exposure. When the temperature of the cave was above $40^{\circ} \mathrm{F}$, the cans were refrigerated with dry ice to keep the peas below this temperature during irradiation. Following irradiation the cans were placed in a refrigerator at $35^{\circ} \mathrm{F}$ from which they were removed within 2 days for heat processing.

* One rad is a dose of ionizing radiation capable of producing energy absorption of $100 \mathrm{erg}$ per $\mathrm{g}$ of tissue. 


\section{Heat Processing}

Six cans of meat, two of which contained thermocouples, were placed in an autoclave where they were heat processed to the desired $F_{0}$ values as previously described (Kempe et al., 1957). The $F_{0}$ value is defined as the number of minutes required to sterilize the can of peas at $250^{\circ} \mathrm{F}$ when the $Z$ value equals 18 . These values were calculated from time-temperature curves obtained from the cans containing thermocouples. For this purpose Schultz's graphical modification of Ball's General Method (Schultz and Olson, 1940) was used, and a $Z$ value of 18 was assumed. Following heat processing, the cans were incubated at $85^{\circ} \mathrm{F}$.

\section{Spores}

The spores of anaerobic bacteria used in these studies were prepared and used as previously described (Kempe et al., 1954).

\section{E. Controls}

Kight control cans were used. Four of these were not inoculated and four were selected at random from the experimental cans. All eight were then incubated at $85^{\circ} \mathrm{F}$. Generally the noninoculated cans swelled within three weeks while gas usually developed within one week in the inoculated cans. This indicated that conditions suitable for microbiological growth were present. However, this did not conclusively demonstrate viability of the inoculum in the peas, since the non-inoculated peas contained bacteria.

When Clostridium botulinum 213 B was used for the inoculum, mouse inoculation tests established the presence or absence of $\mathrm{B}$ type toxin in the peas (Kempe et al., 1954). Occasionally this type of toxin was also recovered from non-inoculated control cans which indicated that the peas contained $C$. botulinum type $\mathrm{B}$ spores when originally frozen. For this reason, the $F_{0}$ required to sterilize non-inoculated canned peas was established by control runs.

\section{Results}

Data for a typical run are shown in T'able I. 'I'wo series of runs were conducted. In the first series, shown in Table II and Fig. 1, 
Table I. $\quad F_{0}$ values required to sterilize canned green peas packed in No. 1 picnic tin cans, inoculated with PA 3679 spores, and irradiated with gamma rays from cobalt-60 before heat processing

Run No. CP 6

Can Size

Product

Inoculum

Irradiation

Processing temperature

Incubation temperature
No. 1 Pienic $(211 \times 400)$

Green Peas

300 PA 3679 spores per can

$0 \cdot 279$ megarad

$230^{\circ} \mathrm{F}$

$85^{\circ} \mathrm{F}^{\mathrm{s}}$

\begin{tabular}{|c|c|c|}
\hline$F_{0}$ & Can No. & Days to gas formation \\
\hline 0.77 & 13 & 4 \\
\hline 0.77 & 14 & 4 \\
\hline 0.77 & 15 & 4 \\
\hline $0 \cdot 77$ & 16 & 4 \\
\hline 1.47 & 17 & $\bar{J}$ \\
\hline $1 \cdot 47$ & 18 & 4 \\
\hline $1 \cdot 47$ & 19 & 4 \\
\hline $1 \cdot 47$ & 20 & 5 \\
\hline $2 \cdot 19$ & 21 & - \\
\hline $2 \cdot 19$ & 22 & $\overline{\mathbf{j}}$ \\
\hline $2 \cdot 19$ & 23 & - \\
\hline $2 \cdot 19$ & 24 & - \\
\hline $3 \cdot 16$ & 9 & - \\
\hline $3 \cdot 16$ & 10 & سـ \\
\hline $3 \cdot 16$ & 11 & - \\
\hline $3 \cdot 16$ & 12 & 一 \\
\hline \multirow{4}{*}{$\begin{array}{l}\text { Controls: } \\
\text { Not inoculated }\end{array}$} & 1 & $\mathbf{3}$ \\
\hline & 2 & - \\
\hline & 3 & 23 \\
\hline & 4 & 6 \\
\hline \multicolumn{3}{|l|}{ Controls : } \\
\hline \multirow[t]{4}{*}{ Inoculated } & 5 & 3 \\
\hline & 6 & 3 \\
\hline & 7 & 6 \\
\hline & 8 & 7 \\
\hline
\end{tabular}

Conclusions: following $0 \cdot 279$ megarad of gammin radiation from cobalt-60, canned peas were sterilized by an $F_{0}$ between $2 \cdot 2$ and $3 \cdot 2$. 
'Table 11. Combined irradiation heat processing treatments required to sterilizo eanned green peas packed in No. 1 picnic tin cans and inoculated with anaerobic bacterial spores
Rın No.
Pre-irradiation megarad
$F_{0}$ range min

a) Series 1: 5,000,000 C. botulinum 213 B spores per can

$\begin{array}{lcc}\text { PB 6 } & 2.33-2.79 & \text { None } \\ \text { PB10 } & >2.79 & \text { None } \\ \text { PB19 } & 2.79-3.29 & \text { None } \\ \text { PB1 } & \text { None } & <1.54 \\ \text { PB 4 } & \text { None } & 1.39-1.82 \\ \text { PB 1 } & \text { None } & >\mathbf{1 . 4 4} \\ \text { PB 3 } & 0 \cdot 465 & 1.03-1.53 \\ \text { PB14 } & 0.465 & 0.60-0.75 \\ \text { PB15 } & 0 \cdot 650 & 0.80-0.92 \\ \text { PB 5 } & 0.930 & 0.36-0.50 \\ \text { PB 8 } & 1.40 & 0.33-0.48 \\ \text { PB18 } & 1.433 & <0.30 \\ \text { PB17 } & 1.96 & <0.06\end{array}$

b) Series 2: 300 PA 3679 spores per can

$\begin{array}{lcc}\text { CP } 2 & 1 \cdot 77-2 \cdot 05 & \text { None } \\ \text { CP 1 } & \text { None } & 4 \cdot 1-4 \cdot 9 \\ \text { CP } 6 & 0 \cdot 279 & 2 \cdot 2-3 \cdot 2 \\ \text { CP 3 } & 0 \cdot 465 & 1 \cdot 39-2 \cdot 25 \\ \text { CP 5 } & 0 \cdot 697 & 0 \cdot 33-0 \cdot 69 \\ \text { CP 4 } & 0 \cdot 930 & 0 \cdot 25-0.49\end{array}$

Non inoculated controls

$\begin{array}{llc}\text { PB } 7 & \text { None } & >0.06 \\ \text { PB 9 } & \text { None } & >0.054 \\ \text { PB12 } & \text { None } & 0.35-0.52 \\ \text { PB13 } & \text { None } & >0.20 \\ \text { PB15 } & \text { None } & 0 \cdot 10-1.10 \\ \text { PB } 7 & >0.465 & \text { None } \\ \text { PB15 } & >0.650 & \text { None }\end{array}$

$5,000,000$ C. botulinum $213 \mathrm{~B}$ spores were used per No. 1 can of peas. In the second series, shown in Table II and Fig. 2, $300 \mathrm{PA}$ 3679 spores were similarly used. These data show that gamma radiation and heat are synergistic when used together for processing canned peas. Less of either form of energy was needed for sterilization when combined with the other than when used alone. 


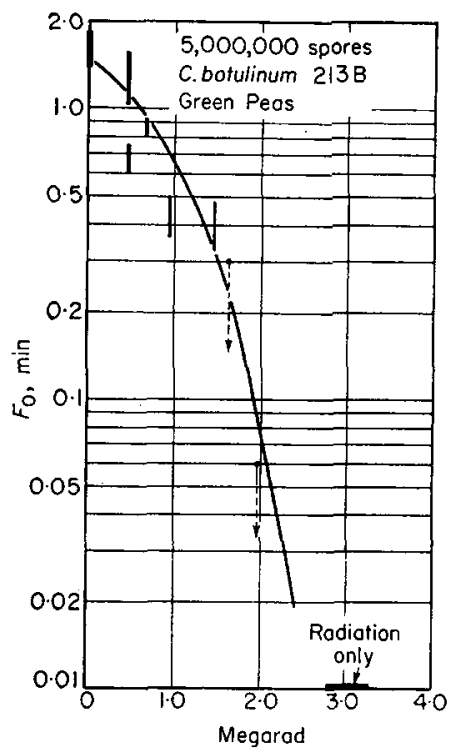

Fig. 1. $F_{0}$ required to sterilize green peas packed in No. 1 picnic tin cans, inoculated with 5,000,000 C. botulinum 213 B spores per can and irradiated with gamma rays from cobalt-60 before heat processing

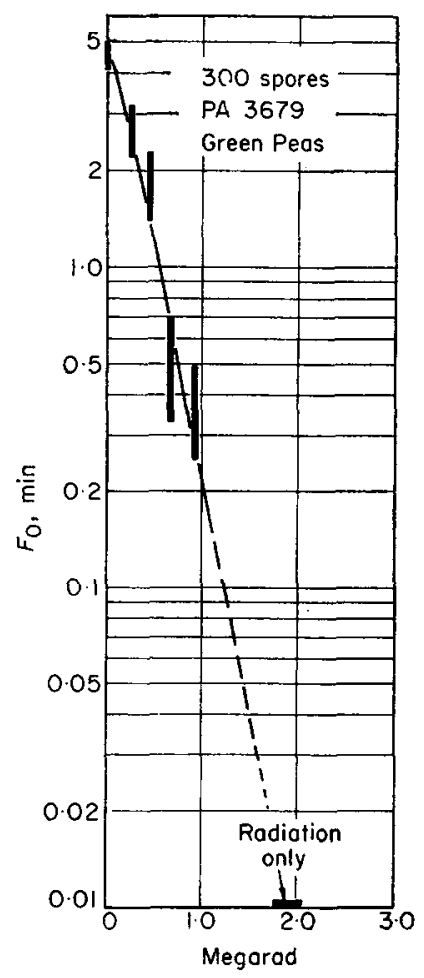

Fig. 2. $F_{0}$ required to sterilize green peas packed in No. 1 picnic tin cans, inoculated with 300 PA 3679 spores per. can, and irradiated with gamma rays from cobalt-60 before heat processing

Following 1.2 megarad of gamma radiation an $F_{0}$ of 0.5 sterilized the peas whether they were inoculated with $5,000,000 \mathrm{C}$. botulinum $213 \mathrm{~B}$ or $300 \mathrm{PA} 3679$ spores. Below 1 megarad pre-irradiation, more heat processing was required to sterilize cans of peas inoculated with 300 PA 3679 spores than was necessary when 5,000,000 $C$. botulinum $213 \mathrm{~B}$ spores were used; above 1 megarad preirradiation, the reverse was true.

\section{Discussion}

The synergistic lethal action of gamma radiation is probably a 
general phenomenon since it is shown to be essentially as pronounced for spores suspended in canned green peas as it has previously been reported to be for such spores suspended in canned beef and in phosphate buffer (Kempe et al., 1957; 1955). It would therefore appear reasonable from a microbiological viewpoint that this synergistic lethal property could be expected to be applied to the sterilization of most canned foods. It also appears that the synergistic action results from sensitization of the spores to heat as a result of irradiation. This effect varies in degree according to the medium in which the spores are suspended so wherever utilization of the effect is considered, the actual application should be studied.

It must be pointed out that the combined irradiation-heat processing treatments reported here are minimum values because they are based on a limited number of runs and upon four cans at each level as shown in Table I.

Relevant to the possible improvement in organoleptic values to be derived from combined irradiation-heat processing, Gillies (1959) has recently reported on studies with canned peas. $\mathrm{He}$ found that thermally processed peas were superior to those processed either by gamma radiation alone or by combined irradiation-heat processing. However, he also stated that combination processed peas were significantly better, in most cases, than those processed with radiation alone.

Achnowledgement. This paper reports research undertaken in cooperation with the Quartermaster Food and Container Institute for the Armed Forces, and has been assigned number 936 in the series of papers approved for publication. The views or conclusions contained in this report are those of the authors. They are not to be construed as necessarily reflecting the views or endorsement of the Department of Defence.

The authors also wish to acknowledge the assistance of Ronald E. West and George T. Tsao for assistance in conducting the heat processing work.

Antitoxin was obtained through the courtesy of Dr. Jesse L. Henry of the New York State Department of Health.

\section{References}

Gillies, R.A. Urgunuleptic evaluation of the combined effects of heat and radiation on canned peas. Food Res., 24, 62-67 (1959) 
Kempe, L. L., Graikoski, J. T. and Gillies, R. A. Gamma ray sterilization of canned meat previously inoculated with anaerobic bacterial spores. Appl. Microbiol., 2, 330-332 (1954)

Kempe, L. L. Combined effects of heat and radiation in food sterilization. Appl. Microbiol., 3, 346-352 (1955)

Kempe, L. L., Graikoski, J. T. and Bonventre, P. F. Combined irradiation-heat processing of foods-I. Cooked ground beef inoculated with Clostridium botulinum spores. Appl. Microbiol., 5, 292-295 (1957)

Kempe, L. L., Graikoski, J. T. and Bonventre, P. F. Combined irradiation-heat processing of canned foods-II. Raw ground beef inoculated with Clostridium botulinum 213 B spores. Appl. Microbiol., 7, 131-134 (1959)

Lewis, J. G., Nehemias, J. V., Harmer, D. E. and Martin, J. J. Analysis of radiation fields of two gamma-radiation sources. Nucleonics, 12, 40-44 (1954)

Reed, J. M., Bohrer, C. W. and Cameron, E. J. Spore destruction rate studies on organisms of significance in the processing of canned foods. Food Res., 16, 383-408 (1951)

Schultz, H. W., Cain, R. F., Nordan, H. C. and Morgan, B. H. Concommitant use of radiation with other processing methods for meat. Food Tech. Champaign, 10, 233-240 (1956)

Schultz, O. T. and Olson, F. C. W. Thermal processing canned foods in tin containers. Food Res., 5, 399-407 (1940) 